\title{
Traditional and Novel Herbal Drugs Emerging as Potent Novel Combinations for Managing Morbidities by Pharmacological and Mechanistic Studies
}

\author{
TAPAN BEHL ${ }^{1 *}$, CHANCHAL KUMAR ${ }^{2}$, ROSHAN KUMAR SINGH ${ }^{3}$, \\ TARUNA KATYAL ARORA ${ }^{4}$ AND SANDEEP ARORA ${ }^{5}$ \\ ${ }^{1,5}$ Chitkara College of Pharmacy, Chitkara University, Rajpura, Punjab-140401 \\ ${ }^{2}$ V.P. Chest Institute, University of Delhi, Delhi, India \\ ${ }^{3}$ University of Exeter, United Kingdom ${ }^{4}$ National Institute of Malaria Research, \\ Dwarka, Delhi
}

*Email: tapanbeh131@gmail.com

Received: December. 28, 2017 I Revised: February 25, 2018 I Accepted: March 15, 2018

Published online: May 02, 2018

The Author(s) 2018. This article is published with open access at www.chitkara.edu.in/publications

\begin{abstract}
Background: Herbal drugs are used in treatment of diseases since decades. Major contributing factor for their use is easy availability, less expensive and more belief of common population because of relatively less side effects compared to allopathic medicines. Medicines of natural origin or functional foods in the prevention of disease are the need of hour. Hence, the present review focused on activity of four drugs viz. Withania somnifera,Allium sativum,Curcuma longa andAzadirachta indica and role in different clinical complications.
\end{abstract}

Methods: A thorough review of all the articles, research as well as reviews available regarding the concerned topic was performed. MEDLINE database was searched and English language articles were preferably selected.

Results: Withania somnifera, Allium sativum, Curcuma longa andAzadirachta indicahave shown alleviation in inflammation, diabetes and cancer states. The herbal drugs have shown beneficial effects in the prevention and treatment of these disorders.

Conclusion from these facts:Utilizing this concept, it can be assumed that herbal drugs play an intricate role in safeguarding the health of individuals from life-threatening complications. However, validation and reproducibility

Journal of Pharmaceutical Technology, Research and Management Vol-6, No-1, May 2018 pp. 31-53 
Behl, T

Kumar, C

Singh, RK

Arora, TK

Arora, $\mathrm{S}$ of results in clinical trails should be there in order to confirm the safety and efficacy of these herbal drugs.

Keywords: Herbal plants; Withania somnifera; Alium sativum; Curcuma longa; Azadirachta indica

\section{INTRODUCTION}

Herbal Plants as Therapeutic Agents: Herbal plants have been used in the mitigation and prevention of diseases from prehistoric times. With the advent of civilization and increase of population, the popularity of herbal drugs is also increasing. This can be ascribed because of the increased costs associated with allopathic medicines. Moreover, the fear of side effects and long term adherence to these medications also obscure their use. Traditional herbal drugs are associated with historical and cultural beliefs and has attributed widely to their use in the modern world. The existence of word "herb" comes from Latin word "herba" and French word "herbe". In the modern world, herb refers to plant part namely fruit, seed, stem, bark, flower, leaf, stigma along with the non-woody part from trees and shrubs.

Some primary diseases arise spontaneously such as, diabetes mellitus (DM), cancer, thyroid, inflammatory disorders, depression, cardiovascular diseases and arthritis, Figure 1. Management of these diseases are very important otherwise the consequent outcomes could be more complicated and dangerous. Herbal medicines that are mentioned in the present article may help in disease management and therapy. Diabetes mellitusis continuously increasing day by day worldwide, according to International Diabetes Federation in 2017 an estimated 425 million adults, a total that is set to reach 629 million by 2045 (IDF, 2018). Similarly, cancer and thyroid are also leading enormously. In 2012, according to Cancer Research UK, an estimated 14.1 million new cases of cancer developed worldwide (Cancer Research UK, 2018). According to various studies on thyroid disease, it has been predicted that about 42 million people suffer from thyroid diseases in India (Indian Academy of Sciences, 2011). Depression and cardiovascular disease have become the leading cause of mortality in India, due to the different lifestyle (Srinath et al., 2005). Arthritis is an autoimmune inflammatory disease that affects the joints and surrounding tissues. According to World Health Organization (WHO) have symptomatic osteoarthritisaged over 60 years and about $9.6 \%$ of men and $18.0 \%$ of women suffered worldwide (Rachel et al., 2013). Therefore, it is important to take care of these diseases properly. Herbal medicines could be a better option for management of the disease, herbal medicines may use with combinational therapy. So, this is a high time to know about herbal compounds and find 
better new options. The present review describes anti-inflammatory, antidiabetic, anti-cancer, anti-anxiety, cardioprotective and anti-thyroid disease of four drugs viz. Withania somnifera, Allium sativum, Curcuma longa and Azadirachta indica. Overall representation and involvement of these herbal drugs in different medical complications are mentioned in Figure 1.

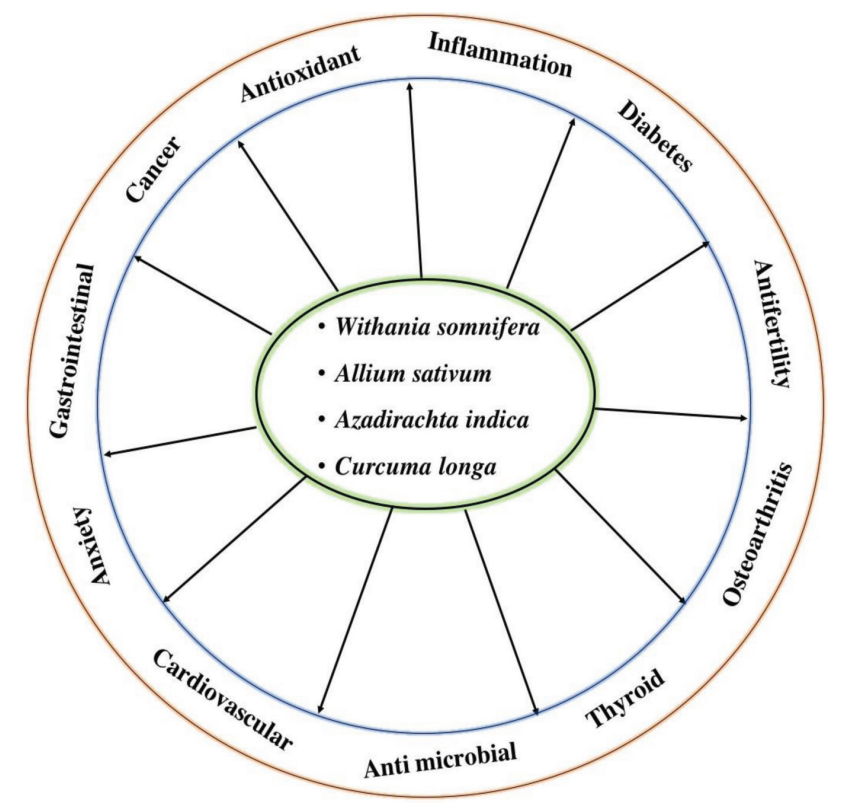

Figure 1: Wheel depicting the use of herbal medicines rejuvenation of different medical complications.

\section{HERBAL PLANTS: USE IN INDIA AND IN GLOBE}

Plants came in existence even before human existence. Natural resources of a country are of utmost importance as they sustain country's economy and health. In view of this reason, the use of traditional herbs in attenuation of diseases have attracted attention of many researchers not only in India but also across the globe. Data from World Health Organization (WHO), reports the increased use of traditional medicine in India and in other parts of world. India has a rich wealth of traditional medicine and around $65 \%$ population of rural area use herbal medicines for their primary health care. Furthermore, in China the use of traditional medicine is approximately $40 \%$ and in Colombia and Chile the use reported is about $40 \%$ and $71 \%$ respectively. The use of alternative
Traditional and

Novel Herbal

Drugs Emerging as Potent Novel

Combinations for Managing Morbidities by Pharmacological and Mechanistic Studies 
Behl, T

Kumar, C

Singh, RK

Arora, TK

Arora, $\mathrm{S}$

or complimentary medicines in developed countries is also common (WHO, 2003). The market of herbal medicines in India is worth US \$1 billion while its cost globally is around US $\$ 62$ billion, with the Chinese herbal medical market about US \$19 billion (Aneesh et al., 2009).

The strategy for use of traditional medicines was made by WHO in the year 2014. This strategy promotes the safe and effective use of traditional medicines by regulating research and integrating products which play an intricate role in mobilizing the health and wellness of mankind (WHO, 2014).

\section{WITHANIA SOMNIFARIA}

Withania somnifaria, commonly known as ashwagandha or winter cherry plays multifarious role in morbid conditions. It derives its name because of smell of its herb like that of horse and post consumption derivation of strength similar to horse. The growth of Withania somniferais best in rainy-season and it attains maturation in relatively dry season. The plant can tolerate a temperature range of $20-38^{\circ} \mathrm{C}$ and can withstand to a temperature even as low as $10{ }^{\circ} \mathrm{C}$. The flowers of the plant are small and green in growing stage, while in ripening stage it becomes orange-red and has elicited milky properties. The flower, leaf and tuberous roots of Withania somniferahave been used for medicinal purposes. It serves as an ingredient in many formulations approved for a variety of clinical conditions (Chatterjee et al., 1995). The astounding role of Withania somniferain treatment of so many vivid health disorders, like diabetes (Andallu et al., 2000), cancer (Rai et al., 2016) and inflammation has made it an important therapeutic component in the modern world (Sangita et al., 2012). Another study conducted by Goreclick et al., 2015 has shown the increase in uptake of glucose in myotubes and adipocytes by leaf and root extract of Withania somnifera (Gorelicket al., 2015). Also, in another study the ployherbal formulation containing Withania somniferaas one of the component has shown anti-diabetic effect in streptozotocin induced diabetes in rats (Gautam and Kalia, 2013).

\subsection{Anti-inflammatory Activity}

The utility of ashwagandha in immunoregulating and anti inflammatory properties have been studied. The entry of pathogen inside the body or traumatic condition leads to infection which intensifies inflammatory processes by innate and adaptive immunity. This consequently alleviates blood pressure and stimulates organ damage Agita et al., 2017).Studies also reported the inhibition of protein denaturation and prevention of immunological damages by Withania somnifera (Gorelick et al., 2015). Study conducted by Gupta et 
al., 2014 showed anti-inflammatory and antioxidant property of root powder of Withania somnifera in collagen-induced arthritic rats (Agita et al., 2017).

\subsection{Anti-Diabetic Activity}

Diabetes mellitus is a convoluted endocrine and metabolic disorder resulting from either insulin insufficiency or insulin dysfunction. It is broadly classified into two types, namely- Type-I Insulin dependent diabetes mellitus (IDDM) and Type-II diabetes mellitus which is also known as non-Insulin dependent diabetes mellitus (NIDDM). The former condition is characterized by destruction of pancreatic beta cells that leads to insufficient insulin production and in latter condition insulin resistance occurs (Kalinowska et al., 2017). Study conducted by Andallu et al., 2000 reported hypoglycemic, diuretic and hypocholesterolemic properties of Withania somniferaroot powder(Andallu et al., 2000).

\subsection{Anti-Cancer Activity}

The cellsperform specific function of division or proliferation according to requirements of body. The abnormal proliferation of the cells leads to development of cancer which has emerged as harbinger to number of complications. The prevalence of cancer is increasing at an alarming rate and requires utmost attention of researchers in development of therapy which should be devoid of side effects. Also, the current available therapies have shown many impairments in form of side effects. Withania somnifaria, a medicinal herb has exhibited significant anticancer activity against cancer cells. The root part of Withania somnifera has shown anti-cancer activity(Rai et al., 2016). Another study conducted with Withania Somnifera root, stem and leaves has shown in vitro anticancer activity against various human cancer cell lines (Yadav et al., 2010). Recent study conducted by Setty et al, on prostate cancer, shows the targeting of interleukin-8 (IL-8) and cyclooxygenase-2 (COX-2) by Withania somnifera leading to impairment in cancer progression (Setty et al., 2017).

\subsection{Anxiety and Depression}

Withania somnifera also haveanxiolytic and antidepressive action in animals. Lakshmi et al 2010 shows comparative study for anti-stress activity with Withania somnifera formulation in mice. Oral dose was given to mice for seven days and significant anti-stress activity was measured by swimming endurance test (Grandhi et al., 1994).Withania somnifera roots extract have been investigated against a rat model of chronic stress (CS). Chronic stress induced significant
Traditional and

Novel Herbal

Drugs Emerging

as Potent Novel

Combinations

for Managing

Morbidities by

Pharmacological and Mechanistic

Studies

$\longrightarrow$


Behl, T

Kumar, C

Singh, RK

Arora, TK

Arora, S

symptoms of hyperglycemia, immunosuppression and mental depression, gastric ulcerations. These CS induced perturbations were brought down byWithania somnifera formulation (Bhattacharya and Muruganandam, 2003).

\subsection{Cardiovascular Protection}

Withania somniferahave shown protective action incardiovascular system against myocardial infarction, stroke and other peripheral vascular disease. Cardiovascular is a most frequent causes of cripple disease and death. Myocardial infraction may interrupt the blood supply and then subsequent damage induced by reperfusion (Kalogeris et al., 2012). Cardiovascular disease may cause by so many metabolically and physiological parameters of the body, Withania somnifera root extract are effective on hypoglycemia, diuretic, and hypocholesterolemic conditions. One one of the study was performed by Andallu and Radhika, on six type 2 diabetes mellitus subjects and six mildly hypercholesterolemic subjects were treated with the Withania somnifera powder extract and got effective result (Andallu ans Radhika, 2000).Increase production of Reacting Oxygen Species also implicated in the pathology of cardiovascular disease. Nuclear factor (erythroid-derived 2)-like 2 (Nrf2) is a transcriptional regulator of phase II antioxidant enzymes. Activation of Nrf2 has been suggested to be imperative role in attenuating oxidative stress associated with Cardiovascular disease. Withania somnifera along with combination of five other herbal plant source effective on activation of Nrf2, therefore upregulation of phase II enzyme $\mathrm{Nrf} 2$ protect cardiomyocytes against Oxidative stress (Reulandet al., 2012).

\subsection{Anti-Thyroid Activity}

Dysfunction of hypothalamic-pituitary-thyroid neuroendocrine cause the bipolar disorder. This thyroid dysfunction has been associated with shift of metabolic and cognitive function (Hendrick et al., 1998). Withania somniferaalso associated with thyrotoxicosis, and administeredto the mice shows significantly elevated level of thyroxine (Gannon et al., 2014). Four subjects were treated with Withania somnifera root extract (600 mg daily) which improved serum TSH, T3 and T4 level significantly as compared to placebo (Sharma et al., 2017). Therefore, Withania somnifera could be a potential herbal medicine for better clinical outcomes.

\section{ALLIUM SATIVUM}

Allium sativum, also known as garlic has been in use from ancient time for folk medicine and in diet as a flavoring agent. Garlic attains importance not 
only because of its use as vegetable but also as a therapeutic and medicinal component in both traditional and modern medicine. Garlic also contains some bioactive compounds among which sulfur-containing non-volatile amino acids (thiosulfinates), alliin or S-allyl-cysteine sulfoxide (ACSO) comprises the most predominant garlic flavor precursors (Hornickova et al., 2010). Moreover, garlic also contains sulfur compounds which are basically responsible for educing it medicinal properties (Banerjee et al., 2003). The enrichment of garlic with these components makes it an important therapeutic agent in the prevention and treatment of diseases like inflammation, diabetes and cancer.
Traditional and

Novel Herbal

Drugs Emerging

as Potent Novel

Combinations

for Managing

Morbidities by Pharmacological and Mechanistic

Studies

\subsection{Anti-inflammatory Activity}

Garlic contains sulfur compounds which are of anti-inflammatory nature. Sulfur compounds inhibit the production of pro-inflammatory cytokines and nitric oxide (NO) (Hodge et al., 2002). Study conducted by Lee et al., 2012 have shown the anti-inflammatory properties of the four sulfur compounds extracted from garlic via hindering production of pro-inflammatory mediators NO and prostaglandin E2 (PGE2) (Lee et al., 2012). Also, the leaves of garlic have shown inhibition of edema in experimental animals (Satarupa et al., 2015).

\subsection{Antibacterial Effect}

Many herbal extracts or remedies have antibacterial activity. That is also a reason to use herbal products in dietary food. Garlic extract have antibacterial activity, inhibit the gram positive and gram negative bacterial growth. Garlic suspensions were extracted and tested at different concentrations and all of them showed an inhibitory effect againstStaphyloccus aureus(Borek, 20016; Eltaweel,2014). Another study conducted on clinical isolated Staphylococcus aureus and Escherichia coli. Antibacterial activity was performed by agar diffusion method (Debella, 2004)) with different concentration of garlic extract, and compared by the chloramphenicol and penicillin as a positive control and distilled water as negative control. Garlic extract showed antibacterial activity against both the microorganism (Abiy \& Berhe, 2016). Multidrug resistance (MDR) bacteria is a major problem worldwide, most of primary antibiotics does not affect the bacterial growth. Garlic extract shows growth inhibition against the multidrug resistant methicillin resistant Staphylococcus aureus (MRSA) and Enterococcus faecalis. The Staphylococcus aureus (MRSA) and Enterococcus faecalis were isolated from clinical patient and antibiotics susceptibility test were done by the disc diffusion method using Muller-Hinton agar medium. For same study was evaluate the antibacterial activity of garlic 
Behl, T

Kumar, C

Singh, RK

Arora, TK

Arora, S

extraction. The efficacy of garlic extracts on Staphylococcus aureusranging from (15-36) $\mathrm{mm}$ diameter zone of inhibition,while that of Enterococcus faecalisranging from (14-33) mm diameter zone of inhibition (Janan et al., 2016).

\subsection{Anti-Diabetic Activity}

Garlic is known as oldest cultivated plant world wide. Garlic supplement have shown a promising role in type-II diabetes mellitus (T2DM) management a promising role in type-II diabetes mellitus (T2DM) management Garlic has also shown to improve insulin sensitivity and the associated metabolic syndrome in animal models (Padiya et al., 2011). Several studies conducted in the past reported increase in insulin production upon the supplementation of garlic. Garlic extract administrations orally showssignificant reduction in serum glucose, total cholesterol, uric acid, triglycerides,creatinine levels. Studies also observed increased level of serum insulin in diabetic rats but not in normal rats(Eidi et al., 2006; Islam \& Choi, 2008).

\subsection{Anti-Cancer Activity}

The use of herbal plants in treatment of cancer is in practice from decades Garlic have allicin and sulfur compounds, which have shown anti-cancer property (Carella et al., 2001). Garlic used as a dietary supplement reduced the risk of cancer. Garlic extract shows. Researchers reported inhibitory effect on cancer (HeLa) cell line in a dose dependent manner by garlic extract and have also measured cytotoxicity effect on HeLa cells (Islam et al., 2011).Another study conducted by Rajeecv et al., 2014 have investigated response of garlic extract on cell lines MCF-7 (Breast cancer), A549 (Lung cancer) and PA-1(Ovary cancer) and has shown efficient cytotoxicity and growth inhibition (Rajeev et al., 2014). Thus, garlic is still being used in India as well as globally for the treatment of numerous kinds of diseases, along with cancer as a natural herbal therapy.

\subsection{Antioxidant Effect}

Antioxidantsare beneficial to the body and they protect from the harmful damage by free radicals. Increase level of free radicals can cause the damage and alter the cell death. Antioxidants may play a role in the prevention of some medical conditions, like cancers, arthritis-related conditions.Antioxidants used in food products can interact with free radicals, which helps in regulation of normal homeostasis. Antioxidant property ofAllium sativumhas been proved scientifically(Jackson et al., 2002). Garlic extract acts as antioxidants to protect cells against reactive oxygen species (ROS) (Chung 2006).Compound 
1,1-diphenyl-2-picrylhydrazyl(DPPH) present in garlic haveradical scavenging activity (Querioz et al., 2009) and superoxide dismutase activity in vitro (Jang et al., 2008). Generation of reactive ROS by heavy metals, which initiates lipid peroxidation, through causing oxidative damage to critical macromolecules like DNA, proteins as well as cell damage (Das et al., 2001).

\subsection{Cardiac Arrest Protection}

Evidences have shown that Allium sativum hasenormous potentrole in protection of cardiac arrest.Allium sativumderived compound such as ajoene have been demonstrated inhibition of platelet aggregation in animal model and reduction of platelet observed by thrombus formation dependent manner (Shah et al., 2014) and augment the fibrinolytic activity (Sogani and Katoch 1981). Study has been performed by Benavides et al shows that vasoactive ability of garlic's sulfur compounds, where by red blood cells convert garlic's organic polysulphides into hydrogen sulphide, a known endogenous cardioprotective (Benavides et al., 2007).In India, a study was conducted on 432 coronary artery patients and the patients were randomly divided into two groups and half of them were supplied with garlic juice in milk, and other group were not supplied with garlic juice. within the three years of the study time results showed nearly twice as many patients had died in the groupin which garlic juice was not supplied (Yeh et al., 2006). Garlic is well reported to scavenge oxidants, increase superoxide dismutase, catalase, glutathione peroxidase, inhibit lipid peroxidation as well as it reduces cholesterol synthesis (Borek, 2006).

\section{CURCUMA LONGA}

Curcuma longa, commonly known as turmeric is not only a spice. Its use as a medicinal herb is in practice from decades. It belongs to ginger family. It contains compounds called as curcuminoids among which the most applicable one is curcumin (diferuloyl methane). Other derived component from the plant are the flavonoid curcumin (diferuloyl methane) and various volatile oils containing tumerone, atlantone and zingiberone with some basic constituents like sugar, proteins and resins. The turmeric content in curcumin is not much high (4\% by weight) (Nagpal and Sood, 2013) Curcumin attributed numerous therapeutic activities among which the most prominent ones are anti-carcinogenic, anti-diabetic and anti-inflammatory (Shehzad et al., 2017).

\subsection{Anti-Inflammatory Activity}

The anti-inflammatory effect of Curcuma longa was attributed majorly due to curcumin acting through suppression of NF-kB band COX-2 activation (Julie
Traditional and

Novel Herbal

Drugs Emerging

as Potent Novel

Combinations

for Managing

Morbidities by

Pharmacological and Mechanistic

Studies

\section{-}


Behl, T

Kumar, C

Singh, RK

Arora, TK

Arora, $\mathrm{S}$

et al., 2009). It also reduces the inflammation by lowering the histamine levels and increasing the production of adrenal glands. It attributes anti-inflammatory properties via inhibiting the biosynthesis of inflammatory prostaglandins from arachidonic acid and neutrophil function. Oral administration of curcumin in insistences of acute inflammation was found to be equally effective as cortisone or phenylbutazone, and half effective in chronic inflammation (Shehzad et al., 2017).

\subsection{Anti-Diabetic Activity}

As discussed in earlier section of this review, curcumin is having antiinflammatory property which reduces the blood glucose level by suppressing inflammation due to hyperglycemia. This stimulates glucose uptake which up regulates GLUT2, GLUT3 and GLUT4 gene expression, consequently increasing insulin secretion from pancreatic tissue and decrease insulin resistance (Ghorbani et al., 2014). A study report suggested that the administration of $0.5 \%$ of curcumin treatment in a diabetic model reduce the infiltration of macrophage in the kidneys of diabetic rats and suppressed the expression proinflammatory cytokine (TNF- $\alpha$ and IL- $\beta$ ). Curcumin has been reported to display protective effects against hyperalgesia in diabetic mice by inhibiting TNF- $\alpha$ release in dose dependent manner and reducing thermal sensation pain in the same (Mrudula et al., 2017). It also activates adenosine monophosphate activated protein kinase (AMPK) which inhibits the accumulation of oxidative stress and lipid in kidneys (Ghorbani, et al. 2014).

\subsection{Anti-Cancer Activity}

Research done on curcumin in various carcinogenesis studies has shown its effect colorectal, breast, gastric, hepatic, and oral cancers (Julie et al., 2009). Curcumin is a highly anti-inflammatory compound which acts by reacting with proinflammatory chemokines and cytokines. It actually a potential inhibitor of myeloid differentiation protein 2, alpha 1-acid glycoprotein, and various enzyme including histone acetyltransferase, cyclooxygenase (COX), inducible nitric oxide synthase (iNOS), human immunodeficiency virus type 1 protease and integrase, DNA methyltransferase and polymerase, protein kinases, focal adhesion kinase (FAK), protein kinase $\mathrm{C}$ (PKC) and phosphorylase-3 kinase. Curcumin is also capable to inhibit cytokinin like interleukins, IL-1, IL-2, IL6 , IL-8, IL-12, tumor necrosis factor alpha (TNF- $\alpha$ ), mitogen activated protein kinase (MAPK), c-Jun N-terminal kinases (JNK), and can bind directly with DNA, RNA and proteins. Various transcription factors binds indirectly to curcumin including $\beta$-catenin, peroxisome, proliferator-activated receptor 
gamma (PPAR $\gamma$ ) and signal transducer and activator of transcription (STAT) proteins (Shehzad et al., 2010). Curcumin is also responsible to develop the expression levels of $\mathrm{p} 53$, reactive oxygen species (ROS) and p21, consequently decreasing the mitochondrial membrane potential (Goel and Aggarwal 2010). Furthermore, curcumin is highly potential and acts anti-carcinogenic by inhibiting several molecular beaten ups including inhibition of NF-kB and COX-2 (increased levels of COX-2 are associated with many cancer types); inhibition of arachidonic acid metabolism through lipoxygenase and scavenging of free radicals generated in this pathway; decreased expression of inflammatory cytokines IL- $\beta$, IL- 6 , and TNF- $\alpha$; and down regulation of protein kinase C (Jurenka, 2009).

\subsection{Gastrointestinal Effects}

Curcuma longa also has several defensive effects on the gastrointestinal tract. Turmeric is generally used in spices for food and helps in inhibits the ulcer formation in gastric tract. It also helps in reduced the intestinal spasm and increase the bicarbonate, gastrin, and secretion of pancreatic enzymes. Study was performed on 25 patients with diagnosed gastric ulcer by endoscopy then $600 \mathrm{mg}$ turmeric powder given five times daily. After five days therapy showed that 48 percent of patient were healed completely without adverse reactions (Khajehdehi et al., 2012). Curcumin may also enhance the efficacy of current chemotherapeutics and, in combination with chemotherapy, may contribute an admirable strategy for treatment of gastrointestinal cancers (Patel et al., 2009). The TPRV1 receptors are widely expressed in the entire gastrointestinal tract and enteric nervous system, and there is evidence that curcumin can inhibit GI nociception and reverse gut hypersensitivity by acting on peripheral terminals (Zhi et al., 2013).Pharmacological properties of curcumin on TRPV1 could be a novel pain modulator (Barbara et al., 2004).

\subsection{Osteoarthritis}

Osteoarthritis is a chronic inflammatory regressive process that affects joints such as the hips, hands, spine, knees. Some studies have shown that curcuma longa ingredients may effective in the treatment of degenerative disease or osteoarthritis. Generally, treatment of osteoarthritis is very tough by conventional treatment, restricted primarily to used nonsteroidal anti-inflammatory drugs, injections of corticosteroids and analgesics. This primarily therapy can lead to adverse effects such as gastrointestinal and cardiovascular problems, notably when used for long periods (Scarpignato et al., 2015). Curcumin seems effective in the pathogenesis of osteoarthritis. The curcuminoids may exhibit an important role as anti-
Traditional and

Novel Herbal

Drugs Emerging

as Potent Novel

Combinations

for Managing

Morbidities by

Pharmacological and Mechanistic

Studies 
Behl, T

Kumar, C

Singh, RK

Arora, TK

Arora, $\mathrm{S}$

inflammatory, down-regulating enzymesas phospholipase A2, cyclooxygenase-2, and lipoxygenases, and reducing TNF- $\alpha$ and interleukins- $1 \beta$ (IL-1 $\beta$ ), IL-6, and IL-8. They also act as inducer of apoptosis in Fibroblast-like synoviocytes (FLS) (Akuri et al., 2017). Curcumin could be a new paradigm and therapeutic opportunity for the treatment and management of osteoarthritis (Henrotin et al., 2013).

\section{AZADIRACHTA INDICA}

The plant Azadirachta indica,known as neem, commonly found in India, Nepal, Bangladesh and Pakistan, has therapeutics application in several diseases like diabetes, cancer, hepatitis, malaria, smallpox and gout. It consists of many effective constituents including nimbidin, nimbolide and limonoids which helps in curing the diseases. Quercetin and $\beta$-sitosterol were first polyphenolic flavonoids purified from fresh leaves of neem and has shown antifungal, antitumor, and antibacterial properties (Govindchari et al., 1998). In this particular section of our article, we have discussed the role of neem in the prevention and treatment of disease like inflammation, cancer and diabetes.

\subsection{Anti-Inflammatory Activity}

Neem have anti-inflammatory properties and studies reported on neem leaf extract showed significant and dose-dependent anti-inflammatory activity in carrageenan based acute inflammation and formaldehyde-induced sub-acute inflammation in rats (Koley et al., 1994). In another study conducted by Naik et al., 2014 neem seed oil (NSO) has shown beneficial effect in carrageenaninduced hind paw edema in albino rats. NSO showed $53.14 \%$ inhibition of edema at the dose $2 \mathrm{mg} / \mathrm{kg}$ body weight after 4 hours of carrageenan injection (Naik et al., 2014). Azadirachta indicaleaf extract also reported protective against cigarette smoke (CS) and lipopolysaccharide (LPS) induced pulmonary inflammation in mice (Lee et al., 2017).

\subsection{Anti-Diabetic Activity}

Role of neem root bark extract is very imperative against diabetes. An experiment conducted on the neem bark root extract (NRE) showed statistically significant result in $800 \mathrm{mg} / \mathrm{kg}$ dose (Patil et al., 2013). Another study was performed to examine the pharmacological hypoglycemic action of Azadirachta indica in diabetic rats and the results revealed significant decrease in glucose levels when compared to control rats (Akter et al., 2013). The compounds extracted from neem leaf has shown predicted binding property with diabetes mellitus type 2 protein enzyme target phosphoenol-pyruvate carboxykinase (PEPCK) 
(Jalil et al., 2013). Thus, Azadirachta indica have significant antidiabetic activity and could be a potential source for treatment of diabetes mellitus.

\subsection{Anti-Cancer Activity}

Reports from previous studies showed the potential of plant extract of neem on inhibition of growth of the malignant cells through apoptosis, tumor suppressor gene and few molecular cascades (Rahmani et al., 2014). It consists of flavonoids and other ingredients which play a crucial role in inhibiting the progression of cancer within the system. Reports suggest that the high rate of flavonoid intake result in decreased risk of cancer (Marchand et al., 2002). Azadirachta indica holds various constituents which activate tumor suppressor gene and inactivate the activity of several genes involved in the cancer progression such as NF-KB, VEGF and P13KAkt. It also activates cyclogenase pathway, apoptosis and NF-kB signaling. Another report showed ethanolic neem extract in accentuation of expression level of proapoptotic genes, like caspase- 8 and caspase-3, and attenuation of expression level of Bcl-2 and mutant p53 in the 7,12dimethylbenz(a)anthracene-induced cancer cells (Subapriya et al., 2006). A component of neem called as nimbolide is also responsible for the down regulation of cell survival proteins, including I-FLICE, cIAP-1, cIAP-2, Bcl-2, surviving and x-linked inhibitor of apoptosis protein, and upregulation of the proapoptotic protein p53 (Gupta et al., 2011). Study conducted by Othman et al., 2012 documented the effect of leaf extract on c-Myc oncogene expression in $4 \mathrm{~T} 1$ breast cancer cells and BALB/c mice and showed significant suppression of c-Myc ongcogene expression compared to the cancer control group (Othman et al., 2012).

\subsection{Anti-microbial Activity}

Azadirachta indicaingredients are known to be effective on inhibition of microbes growth such as viruses, bacteria and pathogenic fungi. Some studies shows antimicrobial efficacy compared with standard irrigant sodium hypochlorite. Zone of growth inhibition of microbes suggest they had antimicrobial properties (Ghonmode et a., 2013). Also suggest that leaf extract of neem showed significantly greater zone of inhibition than sodium hypochlorite (3\%) ((Ghonmodeet a., 2013). Neem leaves extract possess a wide range of antibacterial effect against gram positive and gram negative as well as against Mycobacterium tuberculosis(Chorpra et al., 1952). In-vitro studies showsgrowth inhibition of Vibrio cholerae, Klebsiella pneumoniae, and M. pyogenes(Satyavati et al., 1976).Azadirachta indica leaf extract also suggest in vitro antiviral activity against Vaccinia virus (Anushka et al., 2011),
Traditional and

Novel Herbal

Drugs Emerging

as Potent Novel

Combinations

for Managing

Morbidities by

Pharmacological and Mechanistic

Studies

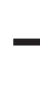

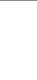


Behl, T

Kumar, C

Singh, RK

Arora, TK

Arora, S

Chikungemya and measles virus, group B coxsackieviruses(Satyavati et al., 1999) and herpes simplex virus type-1 (Tiwari et al., 2010). Azadirachta indica leaves have quercetin and beta- sitosterol polyphenolic flavonoids which also shows antifungul activity (Govindachari et al., 1998). Neem aqueous extracts shows efficacy in the inhibition of spore germination against three sporulating fungi such as C. lunata, $H$. pennisetti, and $C$. gloeosporioides $\mathrm{f}$. sp.mangiferae (Anjali et al., 2013).

Table 1: Representative table showing the effect of herbal medicines on different disease.

\begin{tabular}{|c|c|c|}
\hline Botanical Name & Common Name & Medicinal Uses \\
\hline Withania somnifaria & $\begin{array}{l}\text { Ashwagandha, } \\
\text { Winter Cherry, } \\
\text { Withania }\end{array}$ & $\begin{array}{c}\text { Anti-inflammatory } \\
\text { Anti-diabetic } \\
\text { Anti-cancer } \\
\text { Anxiety and depression } \\
\text { Cardiovascular protection } \\
\text { Anti-thyroid activity }\end{array}$ \\
\hline Allium sativum & $\begin{array}{c}\text { Garlic, } \\
\text { Garlic clove, } \\
\text { Camphor of The poor }\end{array}$ & $\begin{array}{c}\text { Anti-inflammatory } \\
\text { Anti-diabetic } \\
\text { Anti-cancer } \\
\text { Antibacterial } \\
\text { Antioxidant } \\
\text { Cardiac arrest protection }\end{array}$ \\
\hline Curcuma longa & $\begin{array}{c}\text { Turmeric } \\
\text { Haldi }\end{array}$ & $\begin{array}{c}\text { Anti-inflammatory } \\
\text { Anti-diabetic } \\
\text { Gastrointestinal effects } \\
\text { Osteoarthritis }\end{array}$ \\
\hline Azadirachta indica & Neem & $\begin{array}{l}\text { Anti-inflammatory } \\
\text { Anti-diabetic } \\
\text { Anti-cancer } \\
\text { Anti-microbial } \\
\text { Antifertility }\end{array}$ \\
\hline
\end{tabular}

\subsection{Antifertility}

Azadirachta indica oil have novel property for long term and reversible blocking of fertility (Riar et al., 1991). This is seems effective contraceptive of plant 
origin, that is not associated with nontoxic side effects (Updhyay et al., 1991). The intra-vas administration of neem oil resulted in a block of spermatogenesis without affecting testosterone production. The in-vitro performed single intravas administered in to male rats which shows infertile as compare to control, that this strategy could be an alternate approach to vasectomy (Updhyay et al., 1993). Study are also performed by Gbotolorun et al to determine the effects of alcoholic extract of Neem flowers on the estrous cycle, ovulation, fertility and foetal morphology of cyclic in adult Sprague-Dawley rats. That shows estrous cycle of $80 \%$ of the rats was altered with a marked prolongation of the diestrus phase also significant reduction in the number of ova shed. Interestingly no anti-implantion / abortifacient nor teratogenic effect was observed in the rats treated with Neem flower (Gbotolorun et al., 2008). Moreover, plant origin Azadirachta indica that contribute equally in non-invasive in administration, non-hormonal in action, non-toxic and that is relatively long-acting. That herbal medicine could be a better strategy for medicinal complications along with no major side effects.

\section{CONCLUSION}

Prior to use of herbal plants as a part of traditional medicine it is very imperative to have a thorough understanding of its use in past and present. Herbal plant contains diverse constituents which have numerous pharmacological actions thus the key challenge relief on fact of obtaining standardized clinical data. Also, the data indicating the toxicity of herbal drugs is not up to date. The present review article reported anti-inflammatory, anti-diabetic, anti-cancer, anti-anxiety and depression, cardiovascular protection and anti-thyroid activity of herbal drugs shown in Table 1.Future research should be oriented towards exploration of the active component and elucidation of mechanism of action of herbal drug. Systematic standardized research is used by FDA regulation and standard clinical trials are quite limited and need to be actively pursued. Thus, it should be the prime duty of scientists and investigators to perform clinical surveys/trials adhering guidelines at the international level. This would definitely play an intricate role in development of herbal drugs as therapeutic components towards the wealth of mankind.

\section{ACKNOWLEDGEMENT}

Funding: This review received no specific grant from any funding agency in public, commercial or non-profit sectors.

Declaration of Interest: The authors declare no conflict of interest in preparing this article.
Traditional and

Novel Herbal

Drugs Emerging

as Potent Novel

Combinations

for Managing

Morbidities by

Pharmacological and Mechanistic

Studies

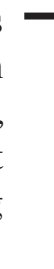


Behl, T

Kumar, C

Singh, RK

Arora, TK

Arora, S
No portion of this manuscript has been submitted for publication elsewhere nor it is under consideration for publication in any other journal, website or textbook.

\section{REFERENCES}

[1] Abiy, E., Berhe, A. (2016) Anti-Bacterial Effect of Garlic (Allium sativum) against Clinical Isolates of Staphylococcus aureus and Escherichia coli from Patients Attending Hawassa Referral Hospital, Ethiopia. Journal of Infectious Diseases and Treatment,2, 2. https://doi.org/10.21767/2472-1093.100023

[2] Agita A, Alsagaff MT. (2017) Inflammation, Immunity, and Hypertension. Acta Med Indones, 49, 158-165. https://doi.org/10.1161/HYPERTENSIONAHA.110.163576

[3] Akter, R., Mahabub-Uz-Zaman, M., Rahman, MS., Khatun, MA, Abdullah AM, Ahmed, NU., Islam, F. (2013) Comparative studies on antidiabetic effect with phytochemical screening of Azadirachta indicia and Andrographis paniculata. IOSR Journal of Pharmacy and Biological Sciences, 5, 122-128. e-ISSN: 2278-3008.

[4] Akuri, M. C., Barbalho, S. M., Val, R. M., \& Guiguer, E. L. (2017). Reflections about Osteoarthritis and Curcuma longa. Pharmacognosy Reviews, 11, 8-12. https://doi.org/10.4103/phrev.phrev_54_16

[5] Andallu, B., Radhika, B. (2000) Hypoglycemic, diuretic and hypocholesterolemic effect of winter cherry (Withania somnifaria, Dunal) root. Indian Jour Exp Bio, 38, 607-609. PMID: 11116534.

[6] Aneesh, T., Hisham, M., Sekhar, M., Madhu, M., Deepa, T. (2009) International market scenario of traditional Indian herbal drugs-India declining. International Journal of Green Pharmacy, 3, 184-190. https://doi.org/10.4103/0973-8258.5627

[7] Anjali, K., Ritesh, K., Sudarshan, M., Jaipal, S. C., Kumar, S. (2013) Antifungal efficacy of aqueous extracts of neem cake, karanj cake and vermicompost against some phytopathogenic fungi. The Bioscan, 8, 671-674.

[8] Anushka,S., Rajendran,P., Vedha, V., Ashok, G., Kannan M., and Karthikeyan, M. (2011) A study on the anti-viral properties of Azadirachta indica (A.Juss, Neem) against HBV, HIV, HSV-I, Vaccinia and Varicella zoster viruses and Coscinium fenestratum (Gaertn.) Colebr, Tree turmeric) against HBV and HIV. Biomedicine, 31, 482-486.

[9] Badam, L., Joshi, SP., Bedekar, SS. (1999) In vitro' antiviral activity of neem (Azadirachta indica. A. Juss) leaf extract against group B Coxsackieviruses. J Commun Dis, 31, 79-90. PMID: 10810594

[10] Banerjee, S. K., Mukherjee, P. K., Maulik, S. K. (2003) Garlic as an antioxidant: the good, the bad and the ugly. Phytotherapy Research, 17, 97-106.

https://doi.org/10.1002/ptr.1281 
[11] Barbara, G., Stanghellini, V., De Giorgio, R., Cremon, C., Cottrell, GS., Santini, D., Pasquinelli, G., Morselli-Labate, AM., Grady, EF., Bunnett, NW., et al. (2004) Activated mast cells in proximity to colonic nerves correlate with abdominal pain in irritable bowel syndrome. Gastroenterology,126, 693-702. PMID: 14988823

[12] Benavides, G. A., Squadrito, G. L., Mills, R. W., Patel, H. D., Isbell, T. S., Patel, R.P., DarleyUsmar, V. M., Doeller, J. E., Kraus, D. W. (2007) Hydrogen sulfide mediates the vasoactivity of garlic. PNAS, 104, 17977-17982. https://doi.org/10.1073/pnas.0705710104

[13] Bhattacharya, S. K., Muruganandam, A. V. (2003) Adaptogenic activity of Withania somnifera: an experimental study using a rat model of chronic stress. Pharmacol Biochem Behav, 75, 547-55. PMID: 12895672

[14] Borek, C. (2006) Garlic reduces dementia and heart-disease risk. J. Nutr,136, 810-812. https://doi.org/10.1093/jn/136.3.810S

[15] Cancer Research UK. (2018)

http://www .cancerresearchuk.org/health-professional/cancer-statistics/ worldwide-cancer

[16] Cerella, C., Dicato, M., Jacob, C., Diederich, M. (2011) Chemical properties and mechanisms determining the anti-cancer action of garlic-derived organic sulfur compounds. Anti-Cancer Agents in Medicinal Chemistry (Formerly Current Medicinal Chemistry-Anti-Cancer Agents), 11, 267-71. https://doi.org/10.2174/187152011795347522

[17] Chatterjee, A., Pakrashi, S. C. (1995) The Treatise on Indian Medicinal Plants. New Delhi, Publication and Information Directorate, 4, 208-212. http://www.niscair.res.in/ActivitiesandServices/Products/products.htm

[18] Chopra, I. C., Gupta, K. C., Nazir, B. N. (1952) Preliminary study of antibacterial substances from Melia azidirachta. Indian. J Med Res, 40, 511-515. PMID: 13061059

[19] Chung, L. Y. (2006). The antioxidant properties of garlic compounds: allyl cysteine, alliin, allicin, and allyl disulfide. J Med Food, 9, 205-13. https://doi.org/10.1089/jmf.2006.9.205.

[20] Daka, D. (2011) Antibacterial effect of garlic (Allium sativum) on Staphyloccus aureus: An in vitro study. African Journal of Biotechnology, 10, 666-669. https://doi.org/10.5897/AJB09.553

[21] Das, K. K., Das, S. N., and Dasgupta, S. (2001) The influence of ascorbic acid on nickel induced hepatic lipid peroxidation in rats. J. Basic Clin. Physiol Pharmacol,12, 187-194. PMID: 11762690

[22] Debella, A. (2004) Procedures in preparation of Medicine from plants. Aartistic Printing Press, Addis Ababa.

[23] Eidi, A., Eidi, M., Esmaeili, E. (2006) Antidiabetic effect of garlic (Allium sativum L.) in normal and streptozotocin-induced diabetic rats. Phytomedicine, 13, 624-9. https://doi.org/10.1016/j.phymed.2005.09.010
Traditional and

Novel Herbal

Drugs Emerging

as Potent Novel

Combinations

for Managing

Morbidities by Pharmacological and Mechanistic

Studies

\section{}


Behl, T

Kumar, C

Singh, RK

Arora, TK

Arora, S
[24] Eltaweel, M. A. (2014) Antibacterial Effect of Garlic (Allium Sativum) On Staphyloccus Aureus: An In Vitro Study. In International Conference on Advances in Environment, Agriculture \& Medical Sciences (ICAEAM'14).

[25] Gannon, J. M., Forrest, P. E. Roy, Chengappa, K. N. (2014) Subtle changes in thyroid indices during a placebo-controlled study of an extract of Withania somnifera in persons with bipolar disorder. Journal of Ayurveda and Integrative Medicine, 5, 241-245. https://doi.org/10.4103/0975-9476.146566

[26] Gauttam, V. K., Kalia, A. N. (2013) Development of polyherbal antidiabetic formulation encapsulated in the phospholipids vesicle system. Journal of Advanced Pharmaceutical Technology \& Research, 4, 108-117. https://doi.org/10.4103/2231-4040.111527

[27] Gbotolorun, S., Osinubi, A., Noronha, C., \& Okanlawon, A. (2008) Antifertility potential of Neem flower extract on adult female Sprague-Dawley rats. African Health Sciences, 8, 168-173.PMID: 19357745

[28] Ghonmode, W. N., Balsaraf, O. D., Tambe, V. H., Saujanya, K. P., Patil, A. K., Kakde, D. D. (2013) Comparison of the antibacterial efficiency of neem leaf extracts, grape seed extracts and 3\% sodium hypochlorite against E. feacalis - an in vitro study. Journal of International Oral Health, 5, 61-66.PMID: 24453446

[29] Ghorbani, Z., Hekmatdoost, A., Mirmiran, P. (2014) Anti-hyperglycemic and insulin sensitizer effects of turmeric and its principle constituent curcumin. International journal of endocrinology and metabolism, 12, e18081. https://doi.org/10.5812/ijem.18081

[30] Goel, A., Aggarwal, B. B. (2010) Curcumin, the golden spice from Indian saffron, is a chemosensitizer and radiosensitizer for tumors and chemoprotector and radioprotector for normal organs. Nutrition and Cancer, 62, 919-30. https://doi.org/10.1080/01635581.2010.509835

[31] Gorelick, J., Rosenberg, R., Smotrich, A., Hanus, L., Bernstein, N. (2015) Hypoglycemic activity of withanolides and elicitated Withania somnifera. Phytochemistry,116,283-289.https://doi.org/.10.1016/j.phytochem.2015.02.029

[32] Govindachari, T.R., Suresh, G., Gopalakrishnan, G., Banumathy, B., Masilamani, S. (1998) Identification of antifungal compounds from the seed oil of Azadirachta indica . Phytoparasitica, 26, 109-116. https://doi.org/10.1007/BF02980677

[33] Grandhi, A., Mujumdar, A.M., Patwardhan, B.A. (1994) Comparative pharmacological investigation of Ashwagandha and Ginseng. J Ethnopharmacol, 44, 131-135.PMID: 7898119

[34] Gupta, A., Singh, S. (2014) Evaluation of anti-inflammatory effect of Withania somniferaroot on collagen-induced arthritis in rats. Pharm Biol, 52, 308-20. https://doi.org10.3109/13880209.2013.835325

[35] Gupta, S. C., Reuter, S., Phromnoi, K., Park, B., Hema, P. S., Nair, M., Aggarwal, B. B. (2011) Nimbolide sensitizes human colon cancer cells to TRAIL through 
reactive oxygen species-and ERK-dependent up-regulation of death receptors, p53, and Bax. Journal of Biological Chemistry, 286, 1134-46.

https://doi.org/10.1074/jbc.M110.191379

[36] Hendrick, V., Altshuler, L., Whybrow, P. (1998) Psychoneuroendocrinology of mood disorders: The hypothalamic-pituitary-thyroid axis. Psychiatr Clin North Am, 21, 277-92. PMID: 9670226

[37] Henrotin, Y., Priem, F., \& Mobasheri, A. (2013). Curcumin: a new paradigm and therapeutic opportunity for the treatment of osteoarthritis: curcumin for osteoarthritis management. SpringerPlus, 2, 56.

https://doi.org/10.1186/2193-1801-2-56

[38] Hodge, G., Hodge, S., Han, P. (2002) Allium sativum (garlic) suppresses leukocyte inflammatory cytokine production in vitro: potential therapeutic use in the treatment of inflammatory bowel disease. Cytometry, 48, 209-215.

https://doi.org/10.1002/cyto.10133

[39] Horníčková, J., Kubec, R., Cejpek, K., Velíšek, J., Ovesná, J., Stavělíková, H. (2010) Profiles of S-alk (en) ylcysteine sulfoxides in various garlic genotypes. Czech Journal of Food Sciences, 28, 298-308. https://doi.org/20103329663

[40] IDF. (2018) https://www.idf.org/our-activities/congress/hyderabad-2018.html

[41] Islam, M. S., Kusumoto, Y., Al-Mamun, M. A. (2011) Cytotoxicity and cancer (HeLa) cell killing efficacy of aqueous garlic (Allium sativum) extract. Journal of Scientific Research, 3, 375-382. https://doi.org/210.3329/jsr.v3i2.6557

[42] Jackson, R., McNeil, B., Taylor, C., Holl, G., Ruff, D., Gwebu, E. T. (2002) Effect of aged garlic extract $\mathrm{n}$ casepase-3 activity in vitro. Nutritional Neuroscience, $\mathbf{5}$, 287-290. https://doi.org/10.1080/10284150290032012

[43] Jalil, A., Ashfaq, U. A., Shahzadi, S., Javed, M. R., Rasul, I., Rehman, S. U., Shah, M., Masoud, M.S. (2013) Screening and design of anti-diabetic compounds sourced from the leaves of neem (Azadirachta indica). Bioinformation, 9, 1031-1035. https://doi.org/10.6026/97320630091031

[44] Janan, M., Sakih, Alaa, T., Monawer, Ismaeil, M., Abdulikhar. (2016) Antibacterial activity of garlic against multidrug resistance Staphylococcus Aureus and Enterococcus faecalis. In Duhok City Journal of University of Duhok.Pure and Eng. Sciences, 19, 114-122.

[45] Jang, G.H., Ha, J.H., Huh, T.L., and Lee, Y.M. (2008) Effect of proton beam on blood vessel formation in early developing zebrafish (Danio rerio) embryos. Archives of Pharmacal Research, 31, 779-785. https://doi.org/10.1007/s 12272-001-1226-1

[46] Julie, S., Jurenka, M. T. (2009) Anti-inflammatory properties of curcumin, a major constituent. Altern Med Rev, 14, 141-53. PMID: 19594223

[47] Kalinowska, A., Orlińska, B., Panasiuk, M., Jamiołkowska, M.,Zasim, A., Florys, B., Wojtkielewicz, K., Łuczyński, W., Głowińska-Olszewska, B., Bossowski, A. (2017) Assessment of preservation of beta-cell function in children with
Traditional and

Novel Herbal

Drugs Emerging

as Potent Novel

Combinations

for Managing

Morbidities by Pharmacological and Mechanistic

Studies 
Behl, T

Kumar, C

Singh, RK

Arora, TK

Arora, S long-standing type 1 diabetes with "ultrasensitive c-peptide" method. Pediatr Endocrinol Diabetes Metab, 23, 130-138.

https://doi.org/10.18544/pedm-23.03.0084

[48] Kalogeris, T., Baines, C. P., Krenz, M., Korthuis, R. J. (2012) Cell Biology of Ischemia/Reperfusion Injury. International review of cell and molecular biology, 298, 229-317.

https://doi.org/10.1016/B978-0-12-394309-5.00006-7

[49] Khajehdehi, P. (2012) Turmeric: Reemerging of a neglected Asian traditional remedy.J Nephropathol,1, 17-22.

https://doi.org/10.5812/jnp.5

[50] Koley, K. M.,Lal, J. (1994) Pharmacological effects of Azadirachta indica(neem) leaf extract on the ECG and blood pressure of rat. Indian journal of physiology and Pharmacology, 38, 223--5. PMID:7814089

[51] Le Marchand, L. (2002) Cancer preventive effects of flavonoids - a review. Biomedicine and Pharmacotherapy, 56, 296-301. PMID: 12224601

[52] Lee, D.Y., Li, H., Lim, H. J., Lee, H. J., Jeon, R., Ryu, J. H. (2012) Antiinflammatory activity of sulfur-containing compounds from garlic. Journal of medicinal food, 15, 992-9.

https://doi.org/10.1089/jmf.2012.2275

[53] Lee, J. W., Ryu, H. W., Park, S. Y., Park, H. A., Kwon, O. K., Yuk, H. J., Shrestha, K. K., Park, M., Kim, J. H., Lee, S., Oh, S. R., Ahn, K. S. (2017) Protective effects of neem (Azadirachta indica A. Juss.) leaf extract against cigarette smoke- and lipopolysaccharide-induced pulmonary inflammation. Int J Mol Med, 40,1932-1940. https://doi.org/10.3892/ijmm.2017.3178

[54] Mrudula, T., Suryanarayana, P., Srinivas, P. N., Reddy, G.B. (2007) Effect of curcumin on hyperglycemia-induced vascular endothelial growth factor expression in streptozotocin-induced diabetic rat retina. Biochemical and biophysical research communications, 361, 528-32.

https://doi.org/10.1016/j.bbrc.2007.07.059

[55] Nagpal, M., Sood, S. (2013) Role of curcumin in systematic and oral health: An overview. Journal of natural science, biology and medicine, 4, 3-7. https://doi.org/10.4103/0976-9668.107253

[56] Naik, M. R., Bhattacharya, A., Behera, R., Agrawal, D., Dehury, S., Kumar, S. (2014) Study of anti-inflammatory effect of neem seed oil (Azadirachta indica) on infected albino rats. Journal of Health Research and Reviews, 1, 66-69. https://doi.org/10.4103/2394-2010.153880

[57] Othman, F. G. M., Peng, S. L., Rahmat, A., Basri, R., Pei, C. P. (2012) Effect of neem leaf extract (Azadirachta indica) on c-Myc oncogene expression in 4T1 breast cancer cells of BALB/c mice. Cell Journal (Yakhteh), 14, 53-60. PMID: 23626938 
[58] Padiya, R., Khatua, T. N., Bagul, P. K., Kuncha, M., Banerjee, S. K. (2011) Garlic improves insulin sensitivity and associated metabolic syndromes in fructose fed rats. Nutrition \& metabolism, 8, 53-60.

https://doi.org/10.1186/1743-7075-8-53

[59] Patel, B. B., Majumdar, A. P. (2009) Synergistic role of curcumin with current therapeutics in colorectal cancer: minireview. Nutr Cancer,61, 842-846. https://doi.org/10.1080/01635580903285106

[60] Patil, P., Patil, S., Mane, A., Verma, S. (2013) Antidiabetic activity of alcoholic extract of Neem (Azadirachta indica) root bark. National Journal of Physiology, Pharmacy and Pharmacology, 3, 142-6. https://doi.org/10.5455/njppp.2013.3.134-138

[61] Queiroz, A. C., Gagliardi, J. F., Forjaz, C. L., Rezk, C. C. (2009) Clinic and ambulatory blood pressure responses after resistance exercise. J Strength Cond Res, Champaign, 23, 571-578. https://doi.org/10.1519/JSC.0b013e318196b637

[62] Rachel, W., Lily, S., and Kamal, A. (2013) Priority Medicines for Europe and the World.www.who.int/medicines/areas/priority_medicines/BP6_12Osteo.pdf

[63] Rahmani, A. H., Alzohairy, M. A., Khan, M. A., Aly, S. M. (2014) Therapeutic implications of black seed and its constituent thymoquinone in the prevention of cancer through inactivation and activation of molecular pathways. EvidenceBased Complementary and Alternative Medicine, 18, 2014. https://doi.org/10.1155/2014/724658

[64] Rai, M., Jogee, P. S., Agarkar, G., dosSantos C. A. (2016) Anticancer activities of Withania somnifaria: Current research, formulations, and future perspectives. Pharm Biol, 54, 189-97. https://doi.org/10.3109/13880209.2015.1027778

[65] Rajeev, N., Sarita, K., Alka, P. (2014) Anticancer activity of Allium sativum (Bulb) polyphenolic compound.Int. J. Pharm. Sci. Rev. Res, 29, 131-134. ISSN 0976 - 044X.

[66] Reuland,D. J., Khademi, S., Castle, C.J., Irwin, D.C., McCord, J.M., Miller, B.F., Hamilton, K. L. (2013) Upregulation of phase II enzymes through phytochemical activation of Nrf2 protects cardiomyocytes against oxidant stress. Free Radic Biol Med, 56, 102-11. https://doi.org/10.1016/j.freeradbiomed.2012.11.016

[67] Riar, S. S., Devakuma, C., Ilavazhagam, G., Kain, A. K., Bardham, J. (1991) Antifertility activities of volatile fraction of Neem oil. Contraception, 44, 319-326. https://doi.org/10.1016/0010-7824(91)90021-7

[68] Sangita, C., Priyanka, C., Protapaditya, D., Sanjib, B. (2012) Evaluation of Anti-inflammatory Effect of Ashwagandha: A Preliminary Study in vitro. Pharmacognosy Journal, 4, 47-49. https://doi.org/10.5530/pj.2012.29.7

[69] Satarupa, P., Aparna, L. I., Priyanka, P. (2015) Anti-inflammatory activity of aquesh extract of Allium sativum leaves. Asian J Pharm Clin Res, 8, 78-80. Online ISSN: 2455-3891
Traditional and

Novel Herbal

Drugs Emerging as Potent Novel

Combinations

for Managing

Morbidities by Pharmacological and Mechanistic

Studies 
Behl, T

Kumar, C

Singh, RK

Arora, TK

Arora, S

[70] Satyavati, G. V., Raina, M. K., Sharma, M., editors. (1976) Medicinal Plants of India Volume 1. New Delhi: Indian Council of Medical Research.

[71] Scarpignato, C., Lanas, A., Blandizzi, C., Lems, W.F., Hermann, M., Hunt, R. H., International, NSAID, Consensus, Group. (2015) Safe prescribing of nonsteroidal anti-inflammatory drugs in patients with osteoarthritis - An expert consensus addressing benefits as well as gastrointestinal and cardiovascular risks. BMC Med, 13, 55. https://doi.org/10.1186/s12916-015-0285-8

[72] Setty Balakrishnan, A., Nathan, A. A., Kumar, M., Ramamoorthy, S., \& Ramia Mothilal, S. K. (2017) Withania somnifera targets interleukin-8 and cyclooxygenase- 2 in human prostate cancer progression. Prostate International, 5, 75-83. http://doi.org/10.1016/j.prnil.2017.03.002

[73] Shah, N. C. (2014) Allium sativum (Garlic): The Folk and Modern uses- Part II. The Scitech Journal, 1, 31-36. ISSN 2348-2311

[74] Sharma, A.K., Basu, I., Singh, S. (2017) Efficacy and Safety of Ashwagandha Root Extract in Subclinical Hypothyroid Patients: A Double-Blind, Randomized Placebo-Controlled Trial. J Altern Complement Med, 24, 243-248. https://doi.org/10.1089/acm.2017.0183

[75] Shehzad, A., Lee, Y. S. (2010) Curcumin: Multiple molecular targets mediate multiple pharmacological actions. Drugs of the future, 35, 113-30. https://doi.org/10.4236/jct.2015.63029

[76] Sogani, R. K., Katoch, K. (1981) Correlation of Serum cholesterol levels and incidence of myocardial infarction with dietary onion and garlic eating habits. $J$. Assoc. Physicians India, 29, 443-446. PMID: 7319999

[77] Srinath, R. K., Shah, B., Varghese, C., Ramadoss, A. (2005) Responding to the threat of chronic diseases in India. Lancet, 366, 1744-1749.

doi: 10.1016/S0140-6736(05)67343-6.

[78] Subapriya, R., Kumaraguruparan, R., Nagini, S. (2006) Expression of PCNA, cytokeratin, Bcl-2 and p53 during chemoprevention of hamster buccal pouch carcinogenesis by ethanolic neem (Azadirachta indica) leaf extract. Clinical Biochemistry, 39, 1080-7. https://doi.org/10.1016/j.clinbiochem.2006.06.013

[79] Tiwari, V., Darmani, N. A., Yue, B. Y. J. T., Shukla D. (2010) In vitro antiviral activity of neem (Azardirachta indica L.) bark extract against herpes simplex virus type-1 infection. Phytotherapy Research, 24, 1132-1140. https://doi.org/10.1002/ptr.3085

[80] Upadhyay, S. N., Dhawan, S., Talwar, G.P. (1993) Antifertility Effects of Neem (Azadirachta indica) Oil in Male Rats by Single Intra-Vas Administration: An Alternate Approach to Vasectomy. Journal of Andrology, 14, 275-281.PMID: 8226307

[81] Updhyay, S., Kaushi, C., Talwar, G. P. (1990) Antifertility effects of Neem oil by single intrauterine administration: A novel method of contraception. Proc The Royal Soc Lond, 242, 175-179. https://doi.org/10.1098/rspb.1990.0121 
[82] Wang, J., Zhang, X., Lan, H., Wang, W. (2017) Effect of garlic supplement in the management of type 2 diabetes mellitus (T2DM): a meta-analysis of randomized controlled trials. Food \& nutrition research, 61, 1377571. https://doi.org/10.1080/16546628.2017.1377571

[83] WHO traditional medicine strategy: 2014-2023, 2014.

[84] World health organization (WHO) (2003) Fifth- sixth world health assembly, A56/18.

[85] Yadav, B., Bajaj, A., Saxena, M., Saxena, A. K. (2010) In Vitro Anticancer Activity of the Root, Stem and Leaves of Withania somnifera against Various Human Cancer Cell Lines. Indian Journal of Pharmaceutical Sciences, 72, 659-663. https://doi.org/10.4103/0250-474X.78543

[86] Yeh, G. Y., Davis, R.B., Phillips, R.S. (2006) Use of Complementary Therapies in Patients with Cardiovascular Disease. Am. J. Card, 98, 673-680.

https://doi.org/10.1016/j.amjcard.2006.03.051

[87] Zhi, L., Dong, L., Kong, D., Sun, B., Sun, Q., Grundy, D., Zhang, G., Rong, W. (2013) Curcumin acts via transient receptor potential vanilloid-1 receptors to inhibit gut nociception and reverses visceral hyperalgesia. Neurogastroenterol Motil, 25, e429-e440. https://doi.org/10.1111/nmo.12145
Traditional and

Novel Herbal

Drugs Emerging as Potent Novel

Combinations for Managing Morbidities by Pharmacological and Mechanistic

Studies 